date is decided for the new vaccine its introduction must be accompanied by an effective publicity campaign. The measles/mumps/rubella vaccine is effective and safe; there are none of the doubts associated with the pertussis vaccine, but many parents still seem unaware of the dangers to which their unvaccinated children are exposed. ${ }^{5}$ The United States, Canada, Sweden, Finland, Czechoslovakia, and Albania are all well on the way to eliminating measles, which still kills around 20 children a year in Britain and leaves others with permanent disability. If preventable, why not prevented?

ToNY SMITH

Deputy editor, $B M F$

1 Anonymous. Vaccine plan unveiled. Yorkshire Post 1987 April 4:3 (col 4).

2 Noah ND. What can we do about measles? Br Med f 1984;289:1476.

3 Rabo E, Taranger J. Scandinavian model for eliminating measles, mumps, and rubella. $\mathrm{Br} \mathrm{Med} \mathcal{J}$ 1984;289:1402-4.

Begg NT, Noah ND. Immunisation targets in Europe and Britain. Br Med f 1985;291:1370-1.

5 Anonymous. Pertussis vaccine [Editorial]. $\mathrm{Br} M e d \mathcal{J}$ 1981;282:1563-4.

\section{European contrasts in obstetrics}

Europe revels in its cultural differences so it is not surprising to find that obstetric practices in its $\mathbf{3 3}$ member states differ. After all, they vary enough in Britain, even within the same hospital, as recent events have shown. What is surprising, however, is the extent to which they vary, given that the maternal and perinatal mortality rates in the industrialised countries in Europe are so similar.

Take home deliveries, for example: in the Netherlands a third of births take place at home, while in Germany and Britain the figure is closer to $1 \%$ despite the strongly voiced demand. Caesarean section rates vary from $4 \%$ to $12 \%$ and operative vaginal deliveries (forceps and vacuum extraction) from $1 \%$ to $13 \%$ of all births. Scotland, with a total operative interventional rate approaching $24 \%$, has one of the highest rates in Europe. ${ }^{1}$ Maternal choice on birth method, birth position, type of analgesia, use of fetal monitors, people in attendance, and episiotomies varies even more. At best women with uncomplicated deliveries get virtually a free hand in determining how they give birth. At worst draconian regimens range from compulsory enemas with two litres of soapy water, still a favourite in some English maternity units, to compulsory 10 day sojourns in the postnatal ward. Access to the baby is limited in some eastern European hospitals to a four hourly visit, when infants are wheeled round for mothers to bottle feed. Maternity benefits are no less disparate, with the length of paid maternity leave ranging from two weeks before and after birth to a generous month or so before and 10 months after.

These observations were among the most striking of those unearthed by an original if necessarily patchy survey of the perinatal services in Europe carried out by a working party set up by the World Health Organisation. Its report, based largely on data collected in 1981 and 1982, was published in 1985 but has not been widely available and received its first major airing in Britain only last week at a meeting of the forum on maternity and the newborn at the Royal Society of Medicine. ${ }^{2}$ Here it was greeted with much enthusiasm, if a measure of criticism.

Professor Alec Turnbull from Oxford pointed out that the data, obtained from questionnaires from the 23 countries who returned them, were incomplete for they were based on national and hospital statistics and did not take the alternative services into account. The attempt to look at these alternative services in eight of the countries had been unsatisfactory because insufficient data had been obtained. $\mathrm{He}$ criticised the anticonventional hospital stance of the report and attributed it to the working party including "too many removed from the sharp end of medicine." His main criticism, however, was that individual countries were not named. This obviously was the major drawback of the report.

Dr Marsden Wagner, chairman of the WHO working party, defended the decision not to name individual countries, saying it had been impossible for political reasons. The information was available, however, in a book Perinatal Health Services in Europe. ${ }^{3}$ Dr Wagner pointed out the main findings of the report and their implications for obstetric care in Britain. Firstly, perinatal surveillance of individuals was good in most of Europe, especially Britain, but there was no adequate surveillance of large groups of patients and no good methods of evaluating systems of care. Feedback on practice to providers was poor, and feedback to the users of the service almost non-existent. Hospitals could easily give their patients information about their rates of caesarean section, epidural anaesthetics, and episiotomy and should do so. Secondly, the balance of power between obstetricians and midwives must be right. In most countries, Britain included, midwives lacked power, which might be a factor behind the current high rates of caesarean section and operative vaginal deliveries. Thirdly, perinatal technology was out of control, and neither its efficacy nor its safety had been evaluated adequately. Fourthly, despite the widespread, almost religious, belief in antenatal care, there were few data to show that it appreciably affected maternal and perinatal mortality rates and no data to show which element of the care was important. Women should also have much more say in defining the structure and nature of the maternity services.

His main message to Britain was to stop concentrating on the technical aspects of perinatal care and improve the social aspects. Our main cause of perinatal mortality was low birth weight babies associated with low maternal socioeconomic status, smoking, and alcohol abuse. More money should be spent on improving the social status of women, ensuring that their housing, diet, and general level of support before, during, and after birth were adequate. This observation came on the very day that the government abolished the $£ 25$ maternity grant and reduced the number of women eligible to claim maternity pay.

Assistant editor, $B M \mathcal{F}$

TESSA RICHARDS

\footnotetext{
1 Bergsiø $P$, Schmidt E, Pusch D. Differences in the reported frequencies of some obstetrical interventions in Europe. Br $\mathcal{F}$ Obstet Gynaecol 1983;90:628-32.

2 World Health Organisation. Having a baby in Europe. Copenhagen: WHO Regional Office for Europe. London: HMSO, 1985. (Public Health in Europe No 26.)

3 Phaff JML, ed. Perinatal health services in Europe. Beckenham, Kent: Croom Helm, 1986.
} 